Research Paper

\title{
Condition of SI-CI Operation with Lean Mixture of Primary Reference Fuel and Hydrogen
}

\author{
Sopheak Rey $^{1)}$ Haruo Morishita $^{1)}$ Nobuhiro Aoyama $^{1)}$ Toru Noda $^{2)}$ Masahiro Shioji $^{1)}$ \\ 1) Kyoto University \\ Yoshida honmachi, sakyo-ku, Kyoto,606-8501 Japan (E-mail: sopheakrey@itc.edu.kh) \\ 2) Nissan Motor Co. , Ltd. \\ 506-2, Kanagawa, Yokohama, Tokyo, 243-0192, Japan
}

Received on July 12,2010

Presented at the JSAE Annual Congress on May, 20 , 2010

\begin{abstract}
In order to control the heat-release rate at homogeneous charge compression ignition (HCCI) operation, the feasibility of spark-assisted compression ignition (SI-CI) combustion was demonstrated with lean mixture of primary reference fuel (PRF) and hydrogen. In this study, the criteria at octane number and hydrogen ratio were investigated using a rapid compression/expansion machine for different equivalence ratios, compression ratios and spark timings. Experimental results of in-cylinder pressure and heat-release rate indicated possible advantageous characteristics of SI-CI operation with lower pressure-rise rate and higher engine output. Also, flame images were visualized to observe various combustion forms including HCCI, SI-CI and SI combustions.
\end{abstract}

KEY WORDS: Ignition Engine, Lean-Burn Engine/SI-CI, Primary Reference Fuels, Hydrogen [A1]

\section{Introduction}

Compared to conventional combustion systems, the homogeneous charge compression ignition (HCCI) combustion system is well known for its high thermal efficiency and low pollutant emissions, especially nitrogen oxides $\left(\mathrm{NO}_{\mathrm{X}}\right)$ and particulate matter (PM) [1]. However, HCCI operations are restricted to a narrow range of engine output due to the knocking that occurs at high load and the misfiring that occurs at low load.

To solve the knocking problem, some researchers have attempted to control the ignition in HCCI combustion systems by using conventional gasoline [2]. As for the misfiring problem, control of intake temperature, equivalence ratio, and compression ratio has been investigated with fuels that have low octane numbers [3].

In more recent research, a new concept, which is based on spark-ignition/compression-ignition (SI-CI) combustion, has been proposed. In the new concept, SI-CI combustion is used to ensure ignitability and to prevent knocking by using SI combustion of a lean pre-mixture to trigger the CI combustion of the end gas [4].

Compared to other approaches, the SI-CI approach can ignite a lean mixture at lower intake temperatures and lower compression ratios. In this study, the results are divided into two parts which the first part examined the possibilities and the changes of combustion forms of SI-CI at fixed-spark timing $\theta_{\mathrm{i}}=$ $20{ }^{\circ}$ ATDC at various octane numbers, hydrogen ratio, compression ratios and equivalence ratios and the range of SI-CI region were exhibited [5-7]. The second part as being examined in this study, the effect of spark timings on the condition of the SICI operation was discussed to understand the possibilities to expand SI-CI range from the previous studies.

In this study, in order to clarify the conditions of the SI-CI operation, experiments were conducted using the rapid compression/expansion machine (RCEM), which provides advantages compared to a conventional engine due to its completely homogeneous charge preparation and the simplicity associated with setting engine conditions. In order to enhance the understanding of the nature of flame development in various combustion forms, flame images were observed for various combustion forms, including HCCI, SI-CI and SI. Also, cylinder pressures and heat-release rates were measured at different equivalence ratios, compression ratios, and spark timings to investigate the criteria of SI-CI for a lean mixture of primary reference fuels (PRFs) with hydrogen addition. After this, combustion forms associated with various spark timings were observed. Tests under various conditions were conducted for each of the different spark timings. From the results of tests for various octane numbers of PRFs and hydrogen ratios, the criteria of SI-CI combustion were determined for different compression ratios, equivalence ratios, and spark timings. Also, based on the rate of pressure rise and the engine output, the conditions of the SI-CI operation were determined.

\section{Experimental setup}

In this experiment, a rapid compression/expansion machine (RCEM), shown in Fig. 1(a), was used, and its specifications are provided in Table 1. The RCEM consisted of a single-cylinder engine driven by a motor, which simulated combustion during piston reciprocation. The compression ratio $\varepsilon$ was changed geometrically by adjusting the thickness of a spacer between the cylinder head and cylinder block. A mixing chamber with a volume of $1,650 \mathrm{~cm}^{3}$ was installed to produce fuel/air mixtures over a wide range of charge pressures and equivalence ratios. 
The fuel/air mixture was introduced into the combustion chamber through an intake valve. The original head of the engine

Table 1: RCEM Specifications and test conditions

\begin{tabular}{l|l}
\hline \hline Bore $\times$ Stroke & $110 \times 106 \mathrm{~mm}$ \\
\hline Compression ratio, $\varepsilon$ & 13,15 \\
\hline Engine speed & $600 \mathrm{rpm}$ \\
\hline Initial temperature, $T_{\mathrm{i}}$ & $97^{\circ} \mathrm{C}$ \\
\hline Cylinder wall temperature, $T_{\mathrm{cw}}$ & $56^{\circ} \mathrm{C}$ \\
\hline Spark timings, $\theta_{\mathrm{i}}$ & -70 to $0{ }^{\circ} \mathrm{ATDC}$ \\
\hline Valve close timing, $\theta_{\mathrm{vc}}$ & $-180^{\circ} \mathrm{ATDC}$ \\
\hline Fuel & $\mathrm{PRF}, \mathrm{H}_{2}$ \\
\hline
\end{tabular}

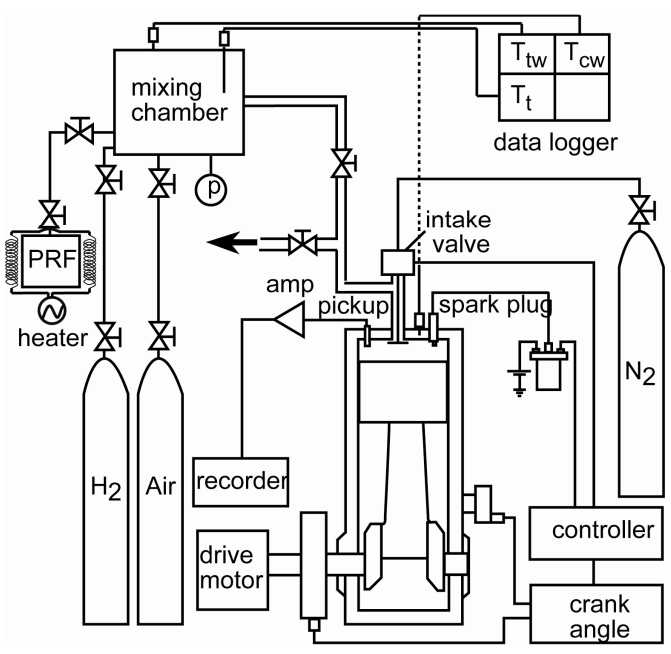

(a)

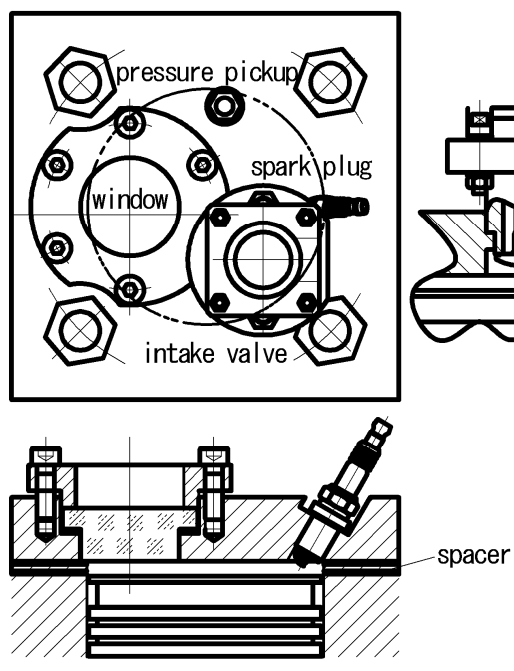

(b)

Fig. 1 Schematic diagram (a) and cylinder head (b) of RCEM

was replaced by a specially-designed combustion chamber, as shown as in Fig. 1(b). A spark plug was mounted at the edge of the combustion space, and the window was installed for visualizing flame images at the opposed side. A Photron highspeed camera (FASTCAM SA1 675K-M1) with a CMOS sensor was used to record flame images at 20,000 fps without any filter.
The cylinder pressure was measured by a piezoelectric pressure transducer. For every experiment, the mixture of gaseous primary reference fuel PRF, hydrogen and air with the assigned equivalence ratio $\phi$ and hydrogen ratio $r_{\mathrm{H}}$ was prepared in the mixing chamber at the pressure $p_{\mathrm{t}}=0.2 \mathrm{MPa}$. Then the RCEM was driven by a motor for at least one minute to ensure the homogeneous mixture. Combustion process started after the intake valve closed at bottom dead center BDC, when the initial temperature $T_{\mathrm{i}}$ of the mixture reached $97^{\circ} \mathrm{C}$, which was measured by a thermocouple in the inner mixing chamber. The initial pressure $p_{\mathrm{i}}=0.125 \mathrm{MPa}$ was measured at $\mathrm{BDC}$ by a strain gauge sensor mounted on the mixing chamber. In this study, experiments were made at a fixed speed of $600 \mathrm{rpm}$ for PRF mixture with different octane numbers of PRF ON from 0 (nheptane) to 100 (iso-octane).

\section{Results and discussions}

Previous works showed the results of three conditions, i.e., Case I for a compression ratio $\varepsilon=13$ and equivalence ratio $\phi=$ 0.45; Case II for $\varepsilon=13$ and $\phi=0.60$; and Case III for $\varepsilon=15$ and $\phi=0.45$ [5-7]. Also, in this research, the effects of compression ratio $\varepsilon$, equivalence ratio $\phi$, hydrogen ratio $r_{\mathrm{H}}$ and octane number $\mathrm{ON}$ on the range of SI-CI operation were explained, and, in addition the research focused on determining the effect of spark timing on the expansion of range of the SI-CI combustion process.

The results of the experiment for each case were analyzed based on the pressure history $p$, the rate of heat release $\mathrm{d} q / \mathrm{d} \theta$, the average combustion temperature $T_{\text {ave }}$, the maximum rate of pressure rise $\mathrm{d} p / \mathrm{d} \theta_{\max }$, the indicated mean effective pressure IMEP, the fraction of CI combustion in SI-CI $r_{\mathrm{CI}}$ and the start timing of CI combustion in SI-CI $\theta_{\mathrm{CI}}$ for certain conditions of $r_{\mathrm{H}}$ and $\mathrm{ON}$ at various spark timings $\theta_{\mathrm{i}}$.

\subsection{Various combustion forms}

In this research, at first, various combustion forms were identified by the investigation of the rate of heat release. Figure 2(a) showed the courses of $p$ and $\mathrm{d} q / \mathrm{d} \theta$ against the crank angle $\theta$ at $\mathrm{ON}=0$ and $\varepsilon=15$ for different $r_{\mathrm{H}}$. In $r_{\mathrm{H}}=0.35$, combustion was achieved in HCCI form without spark and was featured by two stage combustion, in which the first stage was low temperature reaction LTR and the second was high temperature reaction HTR. In $r_{\mathrm{H}}=0.5$, misfiring occurred in HCCI mode, and required a spark ignition. The combustion switched from HCCI to SI-CI mode by using the spark ignition. SI-CI also exhibited two stages of combustion, in which the first stage was SI and the second stage is CI. In $r_{\mathrm{H}}=0.7$, the combustion changed from SICI to SI mode due to high flammability of hydrogen. SI exhibited only single stage of heat-release rate with flame propagation. Such changes of combustion form reflected the flame images in Fig. 2(b). Developments of natural flame luminosity in three combustion forms of HCCI, SI-CI, and SI were exhibited, corresponding with the $p$ and $\mathrm{d} q / \mathrm{d} \theta$ in Fig. 2(a). In $r_{\mathrm{H}}=0.35$, for the [A] : HCCI, ignition was started by multiple sources seen at $\theta$ $=0.5^{\circ} \mathrm{ATDC}$, and combustion occurred very rapidly. Combustion almost completed at $\theta=5.5^{\circ} \mathrm{ATDC}$. In $r_{\mathrm{H}}=0.50$, for the [B] : SI$\mathrm{CI}$, the flame propagation of SI seen at $\theta=3.5^{\circ} \mathrm{ATDC}$, triggered CI seen at $\theta=7.5,8$, and $8.5^{\circ} \mathrm{ATDC}$. The CI flame continued to develop until combustion was complete. In $r_{\mathrm{H}}=0.70$, for [C]: SI, propagation flame was seen at $\theta=3.5^{\circ} \mathrm{ATDC}$. At $\theta=13.5,15.5$, 17 , and $18.5^{\circ} \mathrm{ATDC}$, the two-part flame image that was observed was due to the flame stretch of SI. This flame stretch could be seen clearly at the $\theta=28.5^{\circ} \mathrm{ATDC}$. Among the three combustion forms, HCCI combustion was faster than either SI-CI or SI. SI combustion required a long time to complete the combustion process. 

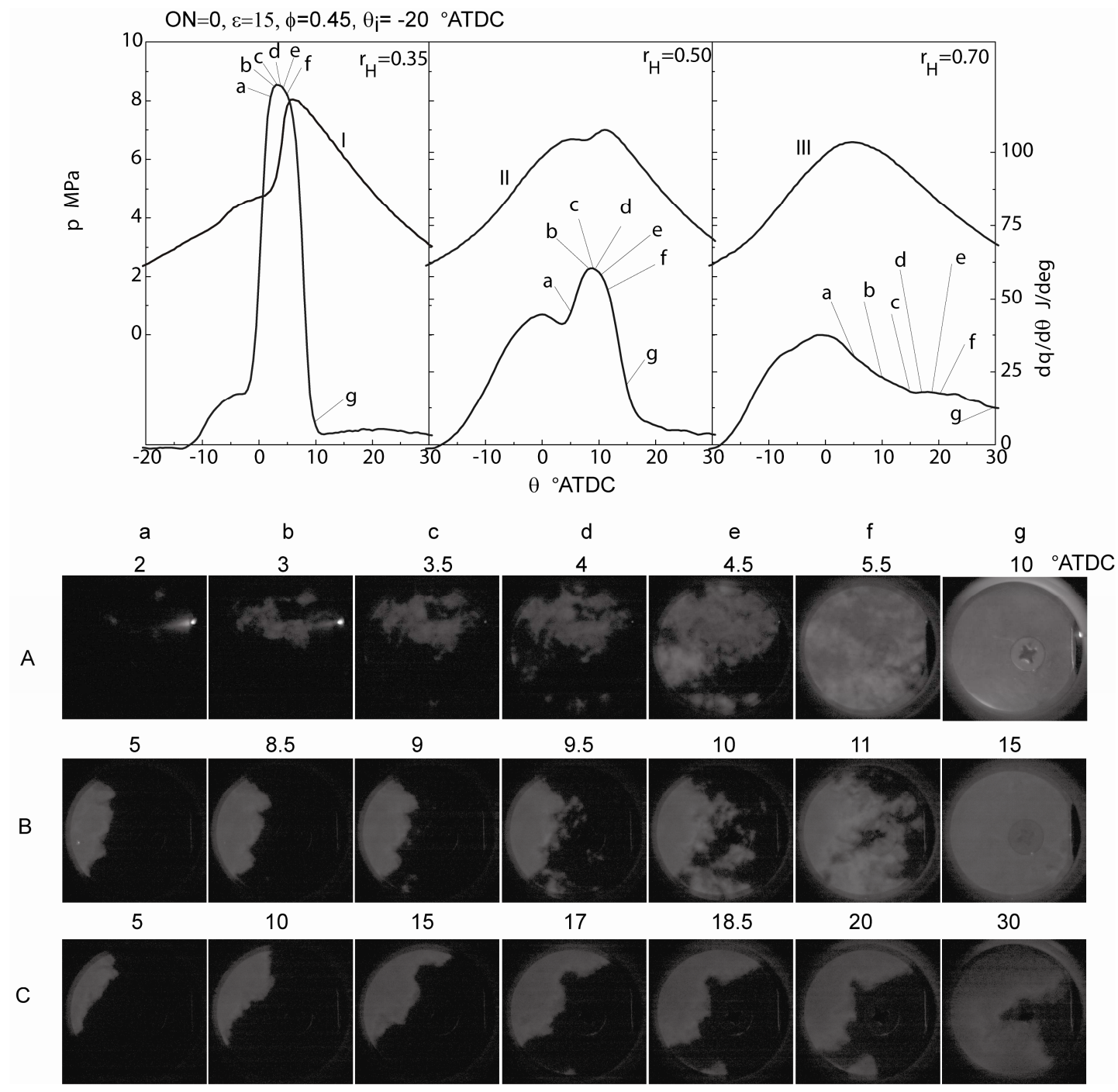

Fig. 2 Histories of pressure and heat-release rate at different $r_{\mathrm{H}}$ for in Case III (a), together with flame images of three combustion forms $[\mathrm{A}]: r_{\mathrm{H}}=0.35(\mathrm{HCCI}),[\mathrm{B}]: r_{\mathrm{H}}=0.50(\mathrm{SI}-\mathrm{CI})$ and $[\mathrm{C}]: r_{\mathrm{H}}=0.70(\mathrm{SI})(\mathrm{b})$ at $\mathrm{ON}=0$ and $\theta_{\mathrm{i}}=-20^{\circ} \mathrm{ATDC}$ in Case III

\subsection{Combustion conditions by spark timings}

Before the condition by spark timings was done, the experiments to clarify various combustion forms with various octane number $\mathrm{ON}$, various hydrogen ratio $r_{\mathrm{H}}$, compression ratio and equivalence ratio at a fixed spark timing $\theta_{\mathrm{i}}=-20^{\circ} \mathrm{ATDC}$ were carried out and the regions of those combustion forms are shown in Fig 3, 5 and 7 without indicating by star plot [6-7]. At the present, the effects of spark timing on SI-CI combustion are focused:

\subsubsection{Condition of $\varepsilon=13$ and $\phi=0.45$ (Case I)}

In this case, the experiment was done to confirm the effect of spark timings on the SI-CI combustion by fixing the hydrogen ratio $r_{\mathrm{H}}$ with $\mathrm{n}$-heptane fuel $\mathrm{ON}=0$. In previous researches [6-7], the regions associated with various $\mathrm{ON}$ and $r_{\mathrm{H}}$ for the different combustion forms of (A) HCCI, (B) SI-CI, (C) SI, and (D) Misfire/Partial combustion (when heat released in the combustion process is less than $70 \%$ of input heat) are shown at a fixed spark timing $\theta_{\mathrm{i}}=-20^{\circ} \mathrm{ATDC}$ for Case I as shown in Fig. 3 was clarified. In this research, the experiments were conducted in condition of $r_{\mathrm{H}}=0.3$ and $\mathrm{ON}=0$ (indicated by star in Fig. 3) with various $\theta_{\mathrm{i}}$ from 0 to $-70^{\circ} \mathrm{ATDC}$ to investigate the characteristics of SI-CI.
In Fig. 4, (a) combustion processes of $p, \mathrm{~d} q / \mathrm{d} \theta$ and $T_{\text {ave }}$ are shown against crank angle $\theta$ and (b) combustion characteristics of IMEP, $\mathrm{d} q / \mathrm{d} \theta_{\max }, \theta_{\mathrm{CI}}$ and $r_{\mathrm{CI}}$ shown at various $\theta_{\mathrm{i}}$. SI-CI form, which is represented by two stages of combustions in heat-release rate, occurs with various $\theta_{\mathrm{i}}$, ranging from -10 to $-40^{\circ} \mathrm{ATDC}$. It is different from HCCI combustion that spark timing can control the ignition and combustion characteristics of SI-CI. Advancing the

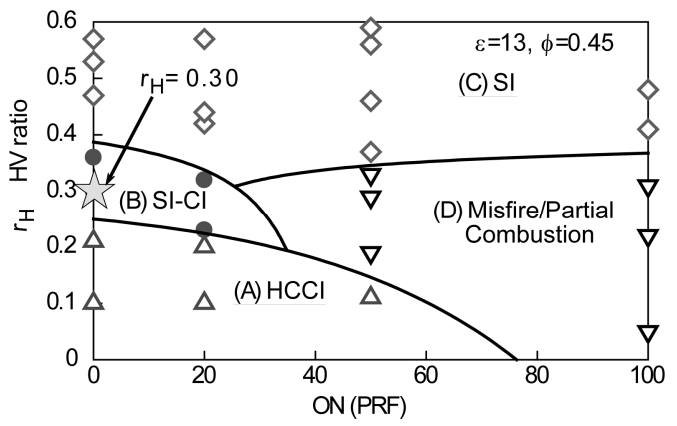

Fig. 3 Region of combustion forms at $\mathrm{ON}$ and $r_{\mathrm{H}}$ in Case I at spark timing $\theta_{\mathrm{i}}=-20^{\circ} \mathrm{ATDC}$ 


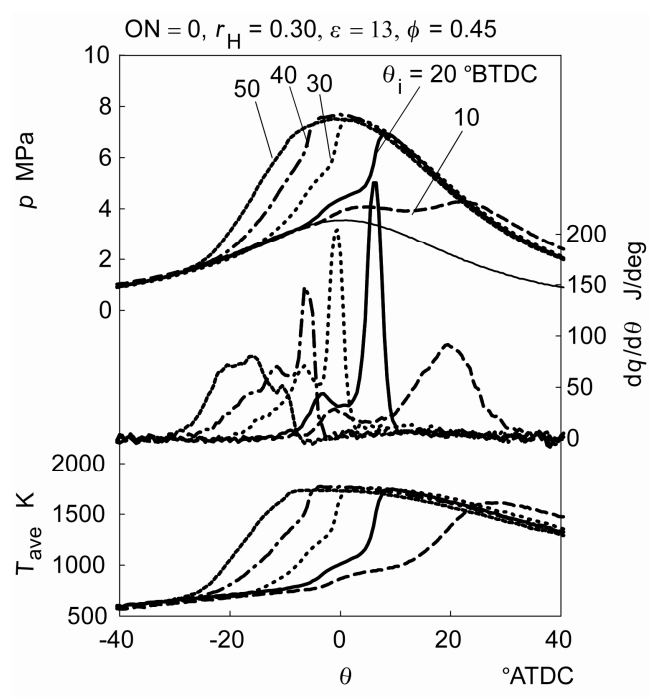

(a) Combustion processes

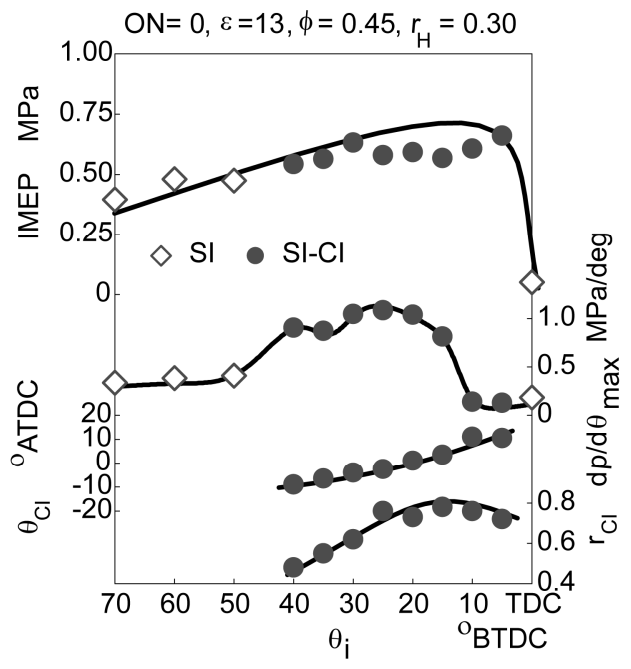

(b) Combustion characteristics

Fig. 4 Change of combustion forms for $r_{\mathrm{H}}=0.30, \mathrm{ON}=0$ at various spark timings in Case I

spark timing further causes the combustion form change from SICI to SI which can be seen at $\theta_{\mathrm{i}}=-50{ }^{\circ} \mathrm{ATDC}$ as single stage combustion in heat-release rate. $T_{\text {ave }}$ follows the trend of heatrelease rate and is lower when spark timing is retarded. In Fig. 4(b), IMEP in SI-CI combustion is greater than that in the SI form. SI-CI combustion has greater IMEP compared to SI may be caused by the fact that the CI combustion in SI-CI combustion that increases the degree of constant volume. From the experimental result, it is clear that IMEP increases when the fraction of CI combustion in SI-CI combustion $r_{\mathrm{CI}}$ increases. Besides, the timing for giving maximum IMEP is about -5 ${ }^{\circ} \mathrm{ATDC}$ in this case. SI-CI gives a greater $\mathrm{d} p / \mathrm{d} \theta_{\max }$ than SI due to the combustion that occurs during CI. No knocking occurs with SI-CI because there are no pressure oscillations during SI-CI form of combustion. Also, $\theta_{\mathrm{CI}}$, is strongly correlated with $\theta_{\mathrm{i}}$ and also affects $r_{\mathrm{CI}}$, which is approximately 0.8 at $\theta_{\mathrm{i}}=-15^{\circ} \mathrm{ATDC}$ in Case I.

\subsubsection{Condition of $\varepsilon=13$ and $\phi=0.60$ (Case II)}

Similar to Case I, the experiment was done to confirm the effect of $\theta_{\mathrm{i}}$ in the region of combustion forms with a condition at

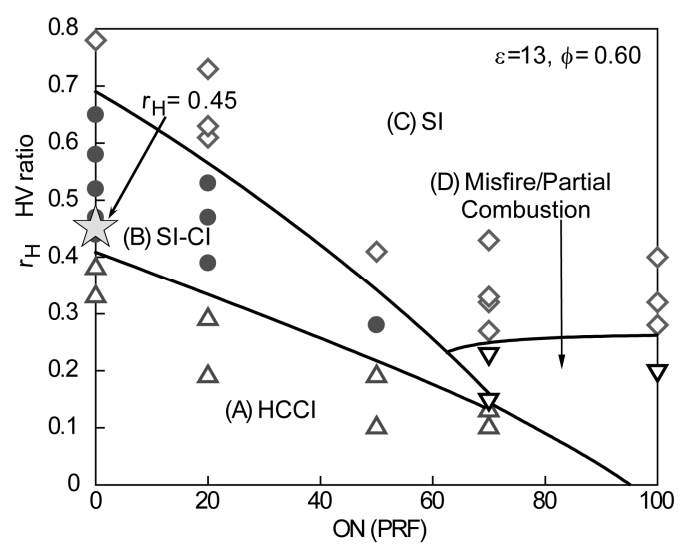

Fig. 5 Region of combustion forms at $\mathrm{ON}$ and $r_{\mathrm{H}}$ in Case II at spark timing $\theta_{\mathrm{i}}=-20^{\circ} \mathrm{ATDC}$

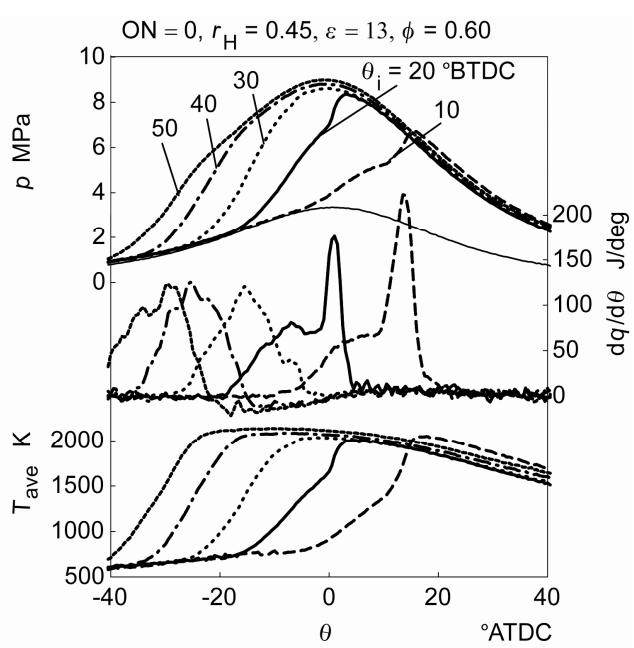

(a) Combustion processes

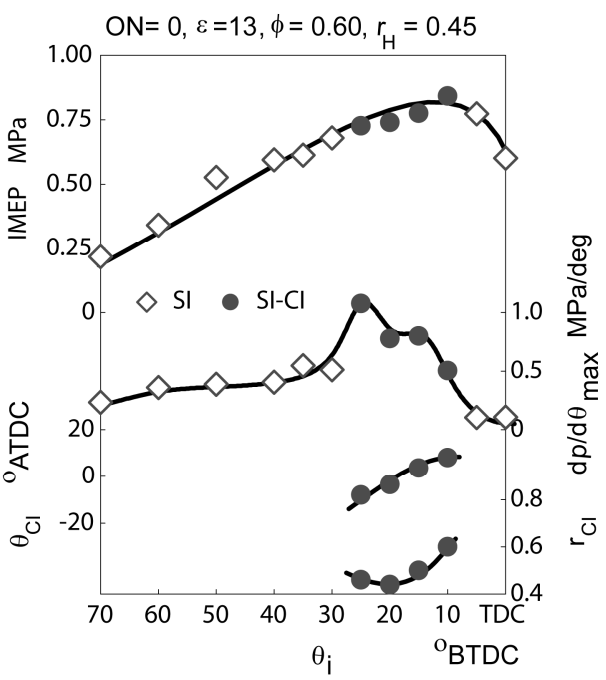

(b) Combustion characteristics

Fig. 6 Change of combustion forms for $r_{\mathrm{H}}=0.45, \mathrm{ON}=0$ at various spark timings in Case II

$\mathrm{ON}=0$ and $r_{\mathrm{H}}=0.45$ for $\varepsilon=13$ and $\phi=0.60$, the condition for which is indicated by star in Fig. 5. Figure 6 shows (a) combustion processes and (b) combustion characteristics with above condition at various $\theta_{\mathrm{i}}$. SI-CI occurs with $\theta_{\mathrm{i}}=-10$ and -20 
${ }^{\circ}$ ATDC, confirmed by investigating the rate of heat release of a two stage combustion. Outside of this range, the combustion takes place in SI form seen as a single stage. Based on the heat-release rate, it is apparent that the results of advancing or retarding spark timings advance or retard started timing of SI and CI of SI-CI. Also, retarded spark timing gives lower $T_{\text {ave }}$. Figure 6(b) shows that SI-CI gives a greater IMEP than SI, and timing for giving high IMEP is at $\theta_{\mathrm{i}}=-10^{\circ} \mathrm{ATDC}$ when combustion is in SI-CI form. The value of $\mathrm{d} p / \mathrm{d} \theta_{\max }$ for SI-CI is greater than that of SI and peak of heat-release rate of CI is also higher than that of SI. As $\theta_{\mathrm{i}}$ is retarded, $\theta_{\mathrm{CI}}$ is also retarded. The value of $r_{\mathrm{CI}}$ reaches its maximum at $\theta_{\mathrm{i}}=-10{ }^{\circ} \mathrm{ATDC}$ which corresponds to maximum IMEP timing.

\subsubsection{Condition of $\varepsilon=15$ and $\phi=0.45$ (Case III)}

In this case, experiments were done to investigate the effects of $\theta_{\mathrm{i}}$ in the region of combustion forms with conditions at various ONs and $r_{\mathrm{H}}$ for $\varepsilon=15$ and $\phi=0.45$, that is, for the conditions indicated by stars in Fig. 7. At $\mathrm{ON}=0$ and $r_{\mathrm{H}}=0.55$, a boundary point between SI-CI and SI was selected, and at $\theta_{\mathrm{i}}=-20^{\circ}$ ATDC, the combustion was in SI form. Figure 8 shows (a) combustion processes and (b) combustion characteristics with above condition at various $\theta_{\mathrm{i}}$. Results explain that the combustion changes from SI to SI-CI when $\theta_{\mathrm{i}}$ advances from $-20^{\circ} \mathrm{ATDC}$ to $-30{ }^{\circ} \mathrm{ATDC}$, which can be only seen in $\mathrm{d} q / \mathrm{d} \theta$, not in $p$ graph. Out of this spark timing range, combustions turn to SI when spark timing is further advanced and ratarded. In this case, it shows that there is a possibility for expanding the range of SI-CI by advancing the spark timing. From the results of combustion characteristics in Fig. 8(b), both IMEP and $\mathrm{d} p / \mathrm{d} \theta_{\max }$ of SI-CI combustion are

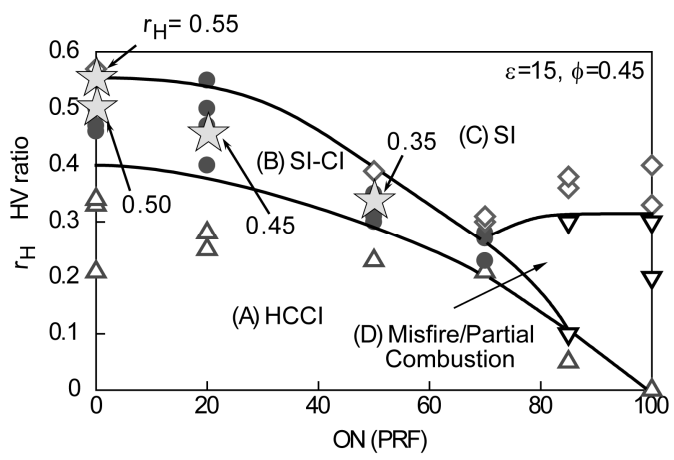

Fig. 7 Region of combustion forms at $\mathrm{ON}$ and $r_{\mathrm{H}}$ in Case III at spark timing $\theta_{\mathrm{i}}=-20^{\circ} \mathrm{ATDC}$ comparable to those of SI combustions. Furthermore, $T_{\text {ave }}$ increases when $\theta_{\mathrm{i}}$ advances. The value of $r_{\mathrm{CI}}$ is around 0.3 at $\theta_{\mathrm{i}}=$

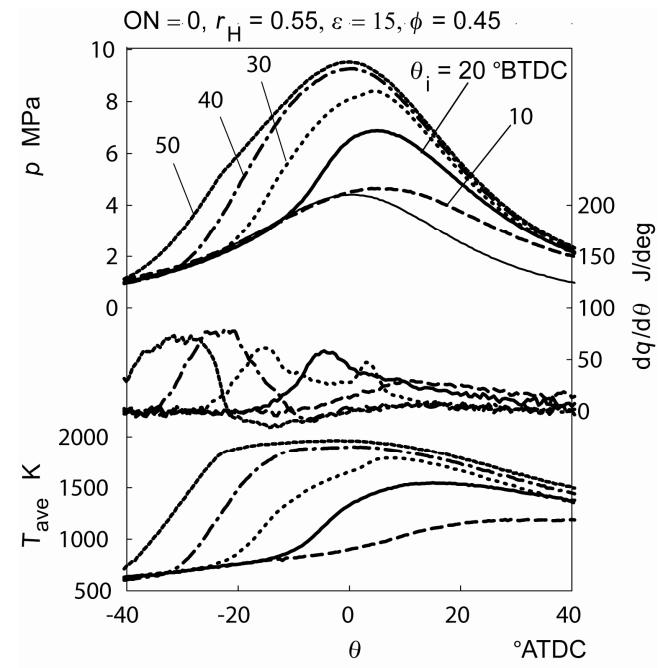

(a) Combustion processes

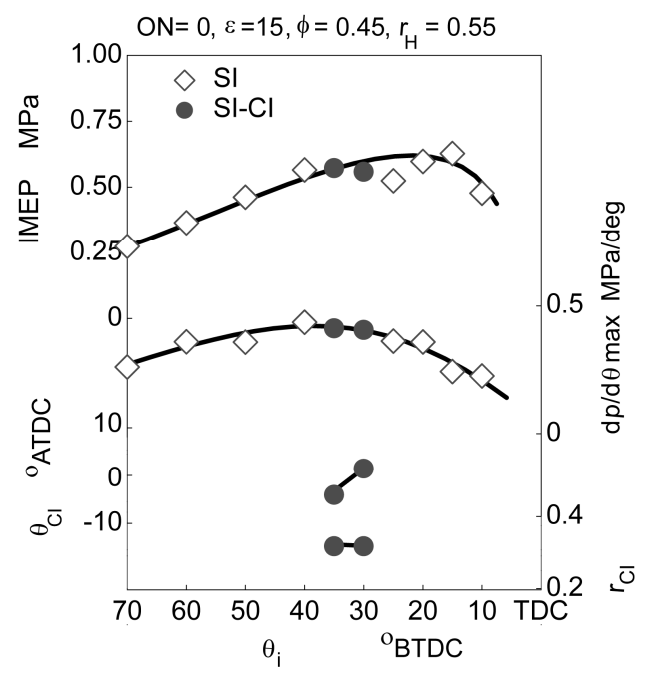

(b) Combustion characteristics

Fig. 8 Change of combustion forms for $r_{\mathrm{H}}=0.45, \mathrm{ON}=0$ at various spark timings in Case III

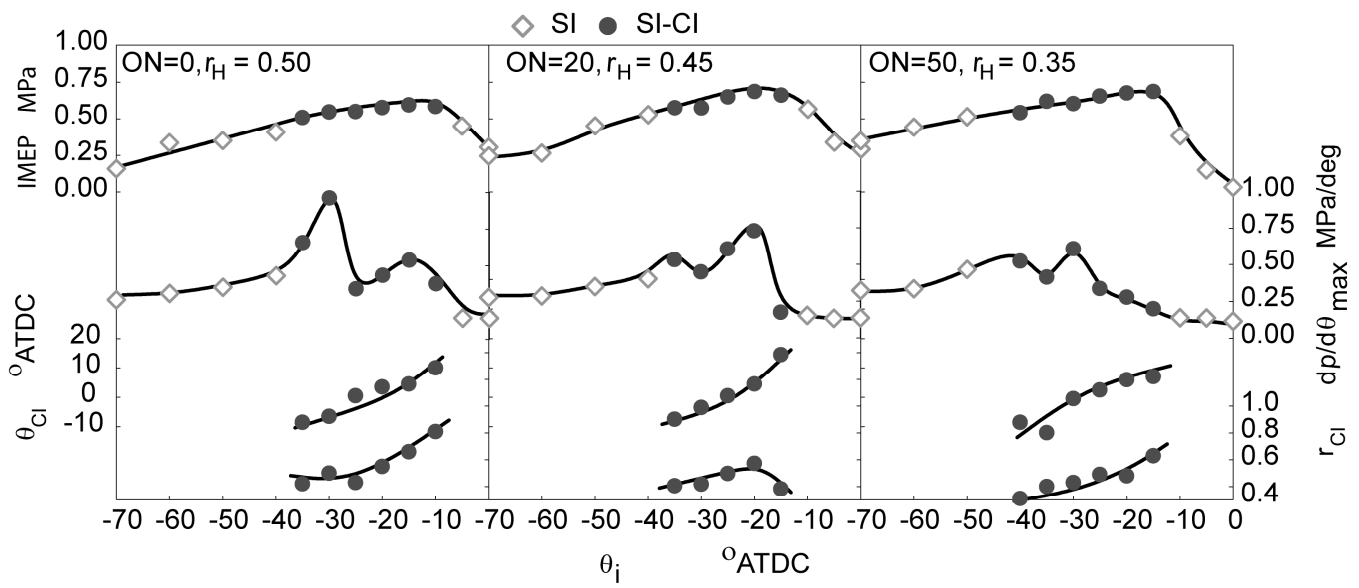

Fig. 9 Combustion characteristics for $\mathrm{ON}=0, \mathrm{ON}=20$ and $\mathrm{ON}=50$ at various $r_{\mathrm{H}}$, spark timings in Case III 
-30 and $-35^{\circ} \mathrm{ATDC}$.

In Fig. 9, the combustion characteristics of various $\mathrm{ON}$ and $r_{\mathrm{H}}$ at various $\theta_{\mathrm{i}}$ are shown. With higher $\mathrm{ON}$ fuels, such as $\mathrm{ON}=20$ and $\mathrm{ON}=50$, range of SI-CI with the effect of $\theta_{\mathrm{i}}$ are comparable compared to $\mathrm{ON}=0$ fuel. The similar range might have resulted from similar overall $\mathrm{ON}$ ( $\mathrm{PRF}$ and $\mathrm{H}_{2}$ ). IMEP slightly increases when $\mathrm{ON}$ increases and $r_{\mathrm{H}}$ decreases. $\mathrm{d} p / \mathrm{d} \theta_{\max }$ of SI-CI are remarked to change with similar trend at $\mathrm{ON}=0,20$ and 50 with $r_{\mathrm{H}}$ $=0.50,0.45$ and 0.35 respectively. At first. $\mathrm{d} p / \mathrm{d} \theta_{\max }$ increases when combustion form changes from SI to SI-CI and CI combustion of SI-CI is found to start before top dead center (TDC). Then, $\mathrm{d} p / \mathrm{d} \theta{ }_{\max }$ changes to decrease after the CI combustion of SI-CI starts after TDC. Next, $\mathrm{d} p / \mathrm{d} \theta_{\max }$ starts to increase again as the ignition delay of CI in SI-CI is long. At last, $\mathrm{d} p / \mathrm{d} \theta_{\text {max }}$ changes to decrease again as CI combustion of SI-CI occurs late in expansion stroke. This trend of $\mathrm{d} p / \mathrm{d} \theta_{\max }$ is found in all cases. Furthermore $\mathrm{d} p / \mathrm{d} \theta_{\max }$ of SI-CI at $\mathrm{ON}=0$ is higher than that of $\mathrm{ON}=20$ and 50. This means that $\mathrm{ON}$ has strong influence on $\mathrm{d} p / \mathrm{d} \theta_{\max }$ and CI. The results of $\theta_{\mathrm{CI}}$ and $r_{\mathrm{CI}}$ show the same trend for $\mathrm{ON}=0,20$ and 50 in Case III, which is similar to that of the previous cases (Cases I and II). Besides, the increase of $r_{\mathrm{CI}}$ correlates with the increase of IMEP

\section{Conclusions}

In this study, the requirements for SI-CI combustion by various spark timings were experimentally investigated, and combustion forms were confirmed by analyzing flame images. Based on the results obtained, the following conclusions are made:

- Images of various combustions, such as HCCI, SI-CI, and SI, show the development of the natural flame. The auto-ignition of end gas to produce the CI of SI-CI combustion is clearly shown.

- SI-CI combustion can occur in a certain range of spark timings. Advanced or retarded spark timings change the combustion form from SI-CI to SI or vice versa.

- For PRF fuel with higher octane number, even the selection of advanced spark timing will not convert SI to SI-CI combustion.

- SI-CI combustion mostly provides greater cycle work when spark timing is adequately controlled. In the experiments, the addition of hydrogen totally eliminates knocking.

- For SI-CI combustion, when the start timing of CI is retarded as a result of retarded spark timing, the ratio of CI increases which results to the increase of engine output. Furthermore, range of SI-CI operation can be expanded by adjusting the spark timing.

The SI-CI combustion form has been investigated with various parameters, such as $\varepsilon, \phi, r_{\mathrm{H}}, \mathrm{ON}$, and $\theta_{\mathrm{i}}$. However, the advancement of equivalence ratio to find the limitation including full load and stochiometric condition because the advance of equivalence ratio to stiochiometric condition was not applied as high NOx emission and possible knock occur. Furthermore, combustion stability and exhaust pollutant emissions are not included in this study due to the limited capabilities of RCEM. Also, the effect of unburned hydrocarbon, heat loss on ISFC and cycle efficiency will be investigated in the future works. Finally, It is our hope that this study will stimulate interest in additional engine tests in the future.

\section{References}

(1) P. M. Najt, D. E. Foster, "Compression-Ignited Homogenous Charge Combustion”, SAE Paper 830264 (1983)
(2) K. Yoshiwa , A. Teraji, H. Miyakubo, K. Yamakuchi, T. Urushihara, "Study of High Load Operation Limit Expansion for Gasoline Compression Ingition Engines", Journal of Engineering for gas turbine and power, Vol.128, 2006.

(3) H. Machrafi , S. Cavadiasa, "An Experimental and Numerical Analysis of the Influence of the Inlet Temperature, Equivalence Ratio and Compression Ratio on the HCCI Auto-Ignition Process of Primary Reference Fuels in an Engine", Fuel Processing Technology, vol. 89, Vol. 89, Nov. 2008, pp. 1218-1226.

(4) T. Noda, S. Rey, M. Shioji, T. Itoh, S. Kimura, "A Study of SI-CI Hybrid Combustion with Low Octane Number Fuel and Hydrogen", Trans. JSAE (in Japanese), vol. 40, P. 20094164, Vol. 40, No. 2, p. 313-318 (2009).

(5) S. Rey, H. Morishita, T. Noda, M. Shioji, "Investigation of SICI Combustion with Low Octane Number Fuels and Hydrogen using a Rapid Compression/Expansion Machine", Edited Book, Journal of Power and Energy, Springer, ISBN: 978-4-431-997788 (2010).

(6) H. Morishita, S. Rey, T. Noda, M. Shioji, "Feasibility of SI-CI Combustion at Lean Mixture of Primary Reference Fuels with Hydrogen Addition", JSAE Proceeding (in Japanese), 3020095704 (2009).

(7) S. Rey, H. Morishita, T. Noda, M. Shioji, "Feasibility of SI-CI Combustion at Lean Mixture of Primary Reference Fuels with Hydrogen Addition”, APAC15 Proceeding, vol. 2, APAC15-312 (2009). 